\title{
Implementation of Solar Cells as an Alternative Energy Source for Automatic Water Tank Filling in Hydroponic System
}

\author{
Yudi Wijanarko ${ }^{1}$ Renny Maulidda ${ }^{1, *}$ Masayu Anisah ${ }^{1}$ Evelina Evelina ${ }^{1}$ Sara Yulida \\ Tarisa Ramadhani ${ }^{1}$ Philips Dharmaraj ${ }^{2}$ Metrina Jasman ${ }^{3}$
}

\author{
${ }^{1}$ Politeknik Negeri Sriwijaya, Palembang, Indonesia \\ ${ }^{2}$ Politeknik Kota Kinabalu, Malaysia \\ ${ }^{3}$ SMK Negeri 1 Indralaya Selatan, Indonesia \\ ${ }^{*}$ Corresponding author. Email: rennymaulidda@polsri.ac.id
}

\begin{abstract}
Agricultural sector requires electrical energy in the on a not-too-wide area called the hydroponic planting system. Hydroponic systems utilize the flow of water and the provision of nutrients. However, sometimes the use of conventional energy does off so that the supply of water and nutrients also stops which results in a decrease in plant quality. Hydroponics is a growing medium that uses water as a growth medium instead of soil, therefore a proper irrigation and nutrition system is needed so that plants can develop normally. One of them is the Nutrient Film Technique, the plant roots grow in a shallow circulating nutrient layer so the plants can get enough water, nutrients and oxygen. The NFT system uses a tank as a place to mix nutrients and water, and the water will flow continuously to the plants with the help of a pump. This system integrates several sensors, namely water flow sensors and float level switch sensors. This system results in the filling of water tanks in hydroponic plants that work automatically.
\end{abstract}

Keywords: Alternative energy, Hydroponic plant, Automatic system, Nutrient film technique

\section{INTRODUCTION}

Alternative power plants can support and provide solutions to meet the needs of electricity sources. One sector that can utilize alternative energy is the agricultural sector. Advances in technology in agriculture, encourage people to grow crops that are adapted to existing environmental conditions. Using a minimalist land with abundant harvests, a modern way of farming was chosen, namely the hydroponic system.

Hydroponics is a growing medium that can use water, coconut fiber, pumice, gravel, and others. As a medium that replaces soil, hydroponics is also environmentally friendly because it does not produce waste that is harmful to the surrounding environment.

Hydroponic systems utilize the flow of water and the provision of nutrients. In practice, conventional electrical energy supplies are used to turn on water pumps to deliver water and nutrients to plant roots. However, sometimes the energy supply goes out so that the supply of water and nutrients also stops which results in a decrease in plant quality.

One of the shortcomings that exist in hydroponics is that in its maintenance, hydroponic plants require a lot of special attention such as water circulation and nutrition. In this case the hydroponic system is a good alternative because it uses water media, so that the concentration of nutrients and distribution of nutrients is easier to control during the cultivation period.

In hydroponic cultivation, the Nutrient Film Technique (NFT) system is known. The NFT system is a method of growing plants in hydroponics which part of the plant roots are submerged in the nutrient solution and partly on the surface of the circulating solution for 24 hours. Cultivation using the Nutrient Film Technique (NFT) hydroponic system for water control and nutrition is done manually. This manual method has the disadvantage that it is very vulnerable to problems including human error. 
With these problems, a solution is needed. In this study, researchers will implement solar panels as an alternative energy for hydroponic plants at SMK Negeri 1 Indralaya Selatan which will provide benefits to the community, provide references in developing the use of renewable energy and support appropriate innovations in the energy sector.

\section{LITERATURE REVIEW}

\subsection{Solar Panel Power Plant}

A solar power plant is a power plant that utilizes sunlight by utilizing a solar panel to be used as electricity where the use of technology from this power plant is to convert photon energy sources from sunlight into electrical energy. This conversion occurs in photovoltaic modules consisting of photovoltaic cells. Photovoltaic cells are thin layers made of pure silicon and other semiconductor materials. If the material gets photon energy, it will excite the electrons from the atomic bonds to become free-moving electrons and eventually will issue a direct current electric voltage.

The use of solar panels can generate electrical energy by using solar energy, this must pay attention to the layout of the solar panel installation which is also currently still fairly static, and oriented in one orientation only, so it is necessary to have an accurate tilt angle of the installation that protrudes or faces direct sunlight, so that solar panels can be installed properly and capture heat energy to the maximum.

\subsection{Hydroponic System}

Hydroponics system comes from the Greek word hydroponic. The word is a combination of two words, namely hydro that means water and ponos that means work. So, hydroponics means working with water. But in general, people plant using soil, so hydroponics no longer uses soil, only uses water that is added with nutrients as a food source for plants. This technology makes it easier for farmers to grow crops. Therefore, this technology is suitable to be applied at this time, considering the increasingly narrow agricultural land.

\subsection{Nutrient Film Technique}

NFT (Nutrient Film Technique) is a method of cultivating plants that plant roots grow in a shallow nutrient layer and circulate for 24 hours, so that plants can get enough water, nutrients and oxygen. Water containing nutrient solution circulates continuously with the help of a pump. In the NFT (Nutrition Film Technology) system, the basic needs that must be met are gutters, storage tanks, and pumps. Hydroponic technology provides a better and more effective way of farming, as well as easier and cheaper gardening technology even in a narrow area. Hydroponic plants are systems that are easy to move, easy to apply, and maintenance free. Most farms with hydroponic systems use less water, produce faster, and of course have achieved good results in a pest-free environment.

\subsection{Float Water Level Switch Sensor}

Water Level Float Switch Sensor is a type of level sensor, a tool used to detect the level of liquid of the tank. Switches is used to control pumps, as indicators, alarms or to control other devices. Float switch uses a mercury switch inside a hinged float. Another common type is a float that raises a rod to move a microswitch. Pattern uses a tube-mounted reed switch; a float, containing a magnet, surrounds the tube and is guided by it. When the float pops a magnet to the reed switch, it closes. Several reeds can be installed in the tube for different level indications.

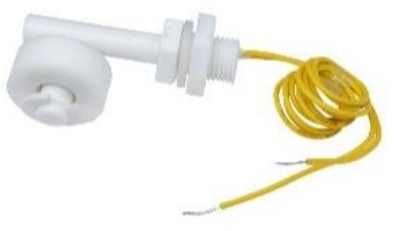

Figure 1 Float Water Level Switch Sensor

\subsection{Water Flow Sensor}

A water flow sensor is a measuring instrument used to measure the discharge or volume of fluid flowing in a closed pipe or open channel such as a river, ditch or culvert. The type of fluid measured with or with water flow can be liquid, gas, or solid. When using water flow to measure flow in terms of flow rate, flow rate and volume or weight of fluid, it has a wide range of applications. The application of a water flow depends on the purpose and benefits, and depends on the situation that needs to be engineered for the installation of the water flow to meet the objectives and benefits. However, the function of the water flow sensor remains unchanged, namely measuring the flow rate.

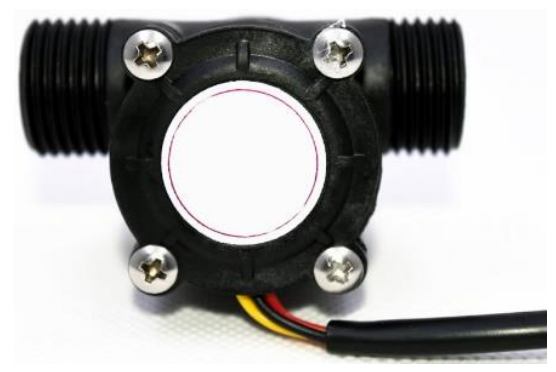

Figure 2 Water Flow Sensor 


\section{METHOD}

\subsection{Hydroponic Design}

Figure 3 below shows the hydroponic system used in this research is the Nutrient Film Technique (NFT) system. Some vegetable crops that are suitable to be applied to this system are pakcoy, lettuce, green spinach and red spinach. Vegetables are complementary foods that are important for health.

To increase the production and growth of vegetable crops, a new technology is needed, so that hydroponics with the NFT system can be an alternative technology in planting. In this way the use of agricultural land can be minimized along with the current narrowing of agricultural land.

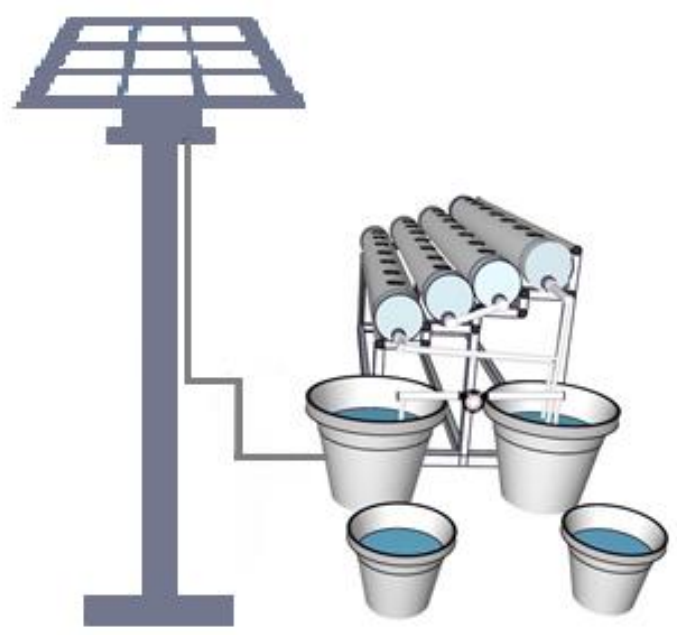

Figure 3 Hydroponic Design

\subsection{Block Diagram}

Block diagram is the most important part in the design. The workings of the automatic water tank filling system on NFT (Nutrient Film Technique) hydroponic plants as a whole can be seen in the block diagram so that the entire block diagram will produce a system that can be functioned.

As in Figure 4 below, the controller that receives input and outputs output sequentially is arranged according to the designed code. Then, the water flow sensor is used to determine the amount of nutrients that enter the tank.

In addition, there is also a float sensor which is used to determine the water level in the tank. Furthermore, Relay as a switch that controls input and output in the form of voltage.

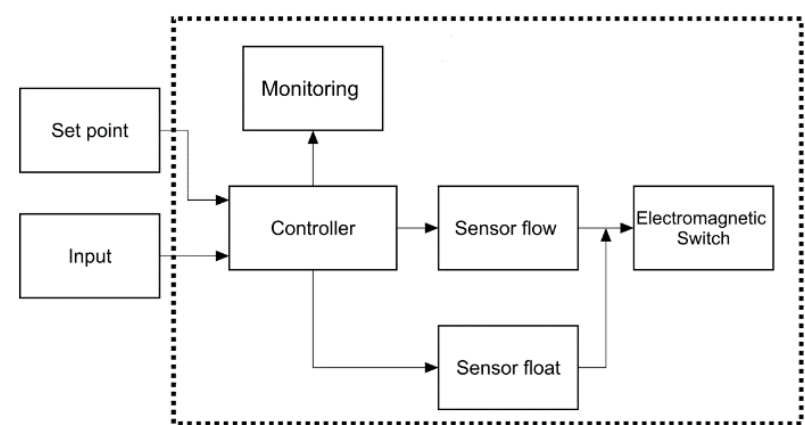

Figure 4. Block Diagram

\subsection{Flow Chart}

The system will start working when the bottom float sensor detects that the liquid has met the set point, when the sensor has not detected the water pump will turn on and if it has fulfilled it then gives a set point on the water flow sensor to activate the fertilizer pump.

When the fertilizer liquid has flowed according to the set point, the fertilizer pump will turn off, if the fertilizer liquid has not flowed according to the set point, the fertilizer pump will turn on. So that the liquid in the tank is filled up to touch the top float sensor or meet the set point, when the liquid has met the set point/reference, the water pump will turn off, while when the liquid has not met the reference, the water pump will turn on. If all processes have been passed then the work process of the tool is complete.

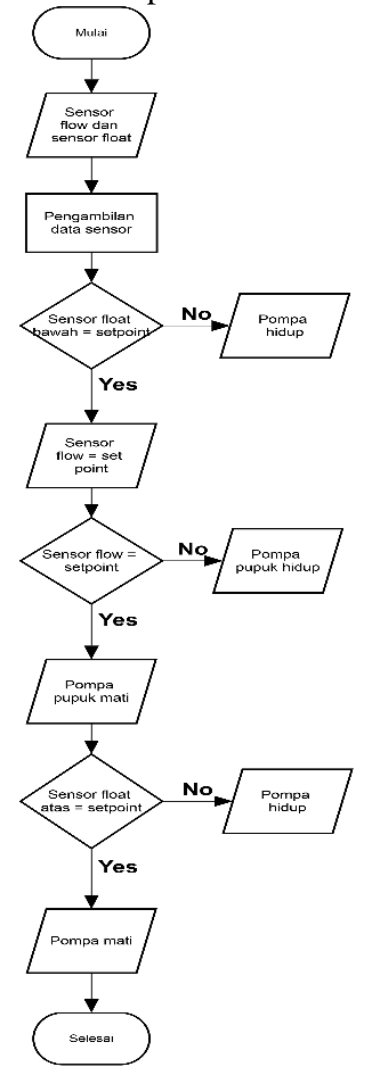

Figure 5 Flow Chart 


\section{RESULT AND DISCUSSION}

To reduce errors in data collection, it is necessary to collect and measure data in real time. Here are some sensor test results:

\subsection{Float Water Level Switch Sensor Testing}

This float sensor test is carried out to give a signal to the pump or buzzer that the water level has reached a certain level that is needed to make effective use of water and fertilizers. So, for water control in this system using sensors to detect the water level in the reservoir. The data on the test results on the sensor can be seen in table 4.1 below.
Based on table 2, it is known that, when the float sensor is not active, the buzzer will be inactive because the fertilizer reservoir is filled. Meanwhile, when the float sensor is active, the buzzer will be active because the fertilizer level in the reservoir is low and the buzzer will be inactive when the fertilizer has been refilled.

\subsection{Water Flow Sensor Testing}

Testing the water flow sensor is done by giving a set point on the panel according to the amount of fertilizer to be flowed. Testing the YF-S201 water flow sensor is carried out to determine whether the sensor has

Table 1. Measuring Result of Float Water Level Switch Sensor

\begin{tabular}{|c|c|c|c|c|c|c|c|}
\hline $\begin{array}{c}\text { Top Float } \\
\text { Sensor }\end{array}$ & $V$ & $\begin{array}{c}\text { Bottom Float } \\
\text { Sensor }\end{array}$ & $V$ & Flow = setpoint & $V$ & \multicolumn{2}{|c|}{ Pump } \\
\hline 0 & 0.01 & 0 & 0.01 & 0 & 0.01 & On & On \\
\hline 1 & 5.02 & 1 & 5.02 & 0 & 0.01 & Off & On \\
\hline 1 & 5.02 & 1 & 5.02 & 1 & 5.01 & Off & Off \\
\hline 0 & 0.01 & 1 & 5.02 & 0 & 0 & On & On \\
\hline 0 & 0.01 & 1 & 5.02 & 1 & 5.01 & On & Off \\
\hline
\end{tabular}

Table 2. Measuring Result of Voltage for Float Water Level Switch Sensor

\begin{tabular}{|c|c|c|c|}
\hline Sensor float & Voltage & Buzzer & Voltage \\
\hline 0 & 0.01 & 0 & 0 \\
\hline 1 & 5.02 & 1 & 12 \\
\hline
\end{tabular}

Table 3. Measuring Result of Water Flow Sensor

\begin{tabular}{|c|c|c|c|}
\hline & Volume (liter) & Time (s) & Debit (I/s) \\
\hline Experiments & 1 & 12 & 42 \\
\hline 1 & 2 & 21 & 99 \\
\hline 3 & 3 & 33 & 172 \\
\hline 4 & 4 & 43 & \\
\hline
\end{tabular}

Table 4. Percentage Error of Water Flow Sensor

\begin{tabular}{|c|c|c|c|c|}
\hline \multirow{2}{*}{ Experiment } & Volume (liter) & Sensor (liter) & Measuring & Error (\%) \\
\hline 1 & $1 \mathrm{~L}$ & 1.1 & 1.15 & 4.3 \\
\hline 2 & $2 \mathrm{~L}$ & 2.1 & 2.3 & 8.6 \\
\hline 3 & $3 \mathrm{~L}$ & 3.1 & 3.35 & 7.4 \\
\hline 4 & $4 \mathrm{~L}$ & 4.1 & 4.2 & 2.3 \\
\hline \multicolumn{2}{r}{} & Average & 5.65 \\
\hline
\end{tabular}

Based on table 1, it is known that, when the sensor is active due to water, it will be switch open and if it is not active due to water, it will be switch closed. The open switch and the closed switch which is the output of the sensor will be read and processed by Arduino which will then instruct the relay to turn on or turn off the water pump. So, it can be seen that the movement of the pump occurs based on the sensor it detects. worked according to the plan. The data on the test results on the

sensor can be seen in table 3 above.

In the table 3 above, it can be seen that the YF-S201 water flow sensor test was successfully carried out four times. Thus, it indicates that the system in the form of a YF-S201 water flow sensor and is displayed on 
the LCD (Liquid Crystal Display) has been operating successfully. The water flow sensor test is carried out to see whether the amount of fertilizer released by the sensor and using an accurate measuring instrument or not can be seen in table 4.4 below.

Based on table 4, the comparison of error in measuring the amount of fertilizer that flows using a flow sensor and measuring cup with a set point that is determined and tested for up to 4 times, it is found that the average percentage error is $5.65 \%$.

\subsection{Discussion}

In designing an automatic water reservoir filling system for NFT (Nutrient Film Technique) hydroponic plants, the working principle of this tool is based on a closed loop control system pattern. In the design of this tool, the flow sensor and float sensor act as inputs which will later provide an output signal to command the pump and buzzer. The flow sensor and float sensor used will be installed in parallel which will be read using the controller, then will be displayed on the LCD.

When the liquid in the reservoir is below the set point of the bottom float sensor, the water pump and fertilizer pump will turn on. The fertilizer pump will be active when the flow sensor has been given a previous set point so that it can run continuously, while the water pump will continue to run until it touches the top float sensor or meets the set point. If the liquid has touched the float sensor, then the water pump will turn off. So, this system will circulate continuously automatically.

The data from the reading of the float water level switch sensor when it is active is a switch opened and when it is not active it is a closed switch while the flow sensor reading data is in the form of liters. On the exact reading there are some differences in the final result data that is read on the flow sensor and the comparison measuring instrument, namely the measuring cup, but the difference is not too significant so it can still be tolerated.

This difference can occur due to several things, one of which is the remaining water flowing in the pump when the relay will give the pump off order. The float sensor that works to indicate the level of the liquid level in the reservoir has been running well and the right test results have been found in giving a signal to the output or output.

\section{CONCLUSION}

Automatic water tank filling system on hydroponic plants that have been designed works well. When the liquid in the tank touches the bottom float sensor, the fertilizer pump and water pump will be on to fill the tank until it touches the top float sensor. If the liquid has touched the top float sensor or has reached the set point/reference, the water pump will be off. While the flow sensor will work after being given a set point on the controller, when the liquid has flowed according to the set point then the fertilizer pump will be off. The results of the comparison of errors between sensor readings and measuring cups found an average error percentage of $5.65 \%$. The result of the percentage error is still tolerable.

\section{REFERENCES}

[1] Suroto, Nurdin, Economic Analysis: Solar Panels Application of NFT (Nutrient Film Technique) Hydroponic System in Bandung, ASEAN Journal of Science and Engineering Education, Volume 1 Issue 1, March 2021 pp 21-30

[2] Siregar, Simon, Marlindia Ike Sari, Rahmi jauhari, Automation system hydroponic using smart solar power plant unit, JurnalTeknologi (Sciences \& Engineering) 78: 5-7 (2016) 55-60

[3] Felipe Jaimes, Brayan Collazos, Emerson Arce, Mario Chauca, Hydroponic System with Automated Hydrolysis Using Renewable Energy Self-Sustainable, MATEC Web of Conferences 256 , 02012 https://doi.org/10.1051/matecconf/201925602012 ICMME 2018

[4] Karoly Ronay, Christian Dragos, Hydroponic green house energy supply based on renewable energy source, $8^{\text {th }}$ international conference interdisclinarity in engineering, INTER-ENG 2014, 9-10 October 2014, Romania

[5] Munawarah, Tholib Hariono, Mashudi Ainun Gofar, Implementation of Solar Cells for Energy Sources in Hydroponic Automation Systems, NEWTON: Networking and Information Technology Vol. 1 No. 1 June 2021, Page. 23 - 27, E-ISSN: 2797-0728 